\title{
Exercise can rescue recognition memory impairment in a model with reduced adult hippocampal neurogenesis
}

\section{Pauline Lafenêtre ${ }^{1,2 *}$, Oliver Leske ${ }^{1,2}$, Zhanlu Ma-Högemeie ${ }^{3}$, Aiden Haghikia $^{2}$, Zoe Bichler ${ }^{1}$, Petra Wahle ${ }^{4 t}$ and Rolf Heumann ${ }^{1+}$}

\footnotetext{
1 Department of Molecular Neurobiochemistry, Faculty for Chemistry and Biochemistry, Ruhr University Bochum, Bochum, Germany

2 Graduate School of Development and Plasticity of the Nervous System, Ruhr University Bochum, Bochum, Germany

3 International Graduate School of Neuroscience, Faculty of Biology and Biotechnology, Ruhr University Bochum, Bochum, Germany

4 Department of Developmental Neurobiology, Faculty of Biology and Biotechnology, Ruhr University Bochum, Bochum, Germany
}

\section{Edited by:}

John F. Cryan, University College Cork, Ireland

\section{Reviewed by:}

Aine Kelly, The University of Dublin, Ireland

Henrietta Van Praag,

National Institutes of Health, USA

${ }^{*}$ Correspondence:

Pauline Lafenêtre, NeuroCentre

Magendie, 146 rue Leo Saignat,

33077 Bordeaux, France.

e-mail: pauline.lafenetre@inserm.fr

${ }^{+}$Shared senior authorship.
Running is a potent stimulator of cell proliferation in the adult dentate gyrus and these newly generated hippocampal neurons seem to be implicated in memory functions. Here we have used a mouse model expressing activated Ras under the direction of the neuronal Synapsin I promoter (named synRas mice). These mice develop down-regulated proliferation of adult hippocampal precursor cells and show decreased short-term recognition memory performances. Voluntary physical activity reversed the genetically blocked generation of hippocampal proliferating cells and enhanced the dendritic arborisation of the resulting doublecortin newly generated neurons. Moreover, running improved novelty recognition in both wild type and synRas littermates, compensating their memory deficits. Brain-derived neurotrophic factor (BDNF) has been proposed to be a potential mediator of physical exercise acting in the hippocampus on dentate neurons and their precursors. This was confirmed here by the identification of doublecortinimmunoreactive cells expressing tyrosine receptor kinase B BDNF receptor. While no difference in BDNF levels were detected in basal conditions between the synRas mice and their wild type littermates, running was associated with enhanced BDNF expression levels. Thus increased BDNF signalling is a candidate mechanism to explain the observed effects of running. Our studies demonstrate that voluntary physical activity has a robust beneficial effect even in mice with genetically restricted neurogenesis and cognition.

Keywords: exercise, recognition memory, adult neurogenesis, proliferation, brain-derived neurotrophic factor, tyrosine receptor kinase $B$

\section{INTRODUCTION}

Wheel running is a general paradigm that has many repercussions on numerous systems, be it cardiovascular, proprioceptive, motor, motivational or general arousal systems. In the last two decades, adult cell proliferation and neurogenesis were found to be differentially regulated by genetic and epigenetic factors (Kempermann, 2002). Indeed, running strongly stimulates adult cell proliferation and neurogenesis in the dentate gyrus but not on the ventricular walls (Brown et al., 2003) and can improve learning and memory abilities in hippocampus-dependent tasks (van Praag et al., 1999; Wojtowicz et al., 2008; Jessberger et al., 2009).

In the hippocampus, Brain-derived neurotrophic factor (BDNF) mRNA and protein have been extensively shown to be increased in response to voluntary physical activity (Berchtold et al., 2001; Johnson et al., 2003; Adlard and Cotman, 2004; Adlard et al., 2004; Russo-Neustadt et al., 2004). BDNF infusion can also increase the number of newly generated neurons of the adult rat hippocampus (Scharfman et al., 2005) even though it is not yet clearly established which type of cells are involved in this response. Recently, nestin-cell specific knock down of tyrosine receptor kinase B (TrkB) in early

Abbreviations: BDNF, brain-derived neurotrophic factor; TrkB, tyrosine receptor kinase B; BrdU, bromodeoxyuridine; GFAP, glial fibrillary acid protein; DCX, doublecortin. proliferating cells completely prevented exercise-induced changes in the hippocampus (Li et al., 2008). However, using the neuronal synapsin promoter for selective knock down of TrkB in differentiated hippocampal neurons did not interfere with voluntary exercise stimulation of early proliferating cells underlining the importance of cell type specific signalling mechanisms during lineage development in adult neurogenesis.

The Ras-mediated extracellular signal-regulated cascade (ERK) pathway is considered as a major BDNF/TrkB intracellular signalling pathway in neurons (Vojtek and Der, 1998). In order to gain further insights into the regulation of newly generated neurons we have used here the synapsin I promoter to express permanently activated Ha-Val12 Ras in mice (named synRas). In a number of experimental paradigms this transgenic activation of Ras in brain neurons prevented lesion-induced neuronal degeneration during postnatal development and in the adult brain (Heumann et al., 2000; Felderhoff-Mueser et al., 2004; Chakrabarty et al., 2007; Makwana et al., 2009). Consistently, also in normal newborn hippocampal neurons there is enhanced cell survival in synRas mice. This was associated with a strongly reduced proliferation of non-neuronal early proliferating cells (Manns et al., in revision).

Besides its neurotrophic effects on survival and differentiation, BDNF activity is acting on branching development of neurons (Borasio et al., 1989; McAllister et al., 1995). Enriched housing 
conditions (Leggio et al., 2005; Stranahan et al., 2007) and exposure to learning paradigms (Moser et al., 1994; Feria-Velasco et al., 2002) also stimulate dendritic arborisation and spine density. Altogether, these data propose BDNF as a potential mediator of the effects of running on adult neurogenesis and branching development.

There is growing evidence that the level of adult neurogenesis is correlated to behavioural performances (Shors et al., 2001; Drapeau et al., 2003; Dalla et al., 2009; Garthe et al., 2009; Hernández-Rabaza et al., 2009). This has been mainly shown in the most common hippocampal-dependent tasks, namely the trace or contextual fear conditioning. However, the link between novelty recognition and adult neurogenesis has only recently been examined in rats (Jessberger et al., 2009). Indeed, recognition memory relies not only on cortical and paracortical regions (Murray et al., 2000) but also on the integrity of the hippocampus. It is assumed to involve episodic working memory dependent on the interactions between CA3 and the dentate gyrus via mossy fibre inputs (Clark et al., 2001; Manns et al., 2003).

In this study, we first examined whether the reduced level of adult cell proliferation observed in the synRas mouse would be associated with lower dendritic arborisation and lower performance in the object recognition test. Besides, we examined whether running, an epigenetic stimulator of adult neurogenesis, could, on the one hand, reverse the strong phenotypes of this mouse and, on the other hand, enhance the behavioural performance of both wild type and transgenic mice. Furthermore, we hypothesised that running-induced rescue effects were mediated by the neurotrophic factor BDNF and we analysed its expression and the type of cells on which it could act.

\section{MATERIALS AND METHODS ANIMALS AND HOUSING}

Two- to three-month-old female synRas and wild type littermate mice, of NMRI background (Heumann et al., 2000) were housed per group of five in standard cages $(21 \mathrm{~cm} \times 16 \mathrm{~cm} \times 14 \mathrm{~cm})$ under a 12-h light: 12-h dark cycle (lights on at 7:30 am) with ad libitum access to food and water. Temperature $\left(18^{\circ} \mathrm{C} \pm 2^{\circ}\right)$ and humidity (70\%) were kept constant. Runner mice were also housed per group of five but in bigger cages $(56 \mathrm{~cm} \times 32 \mathrm{~cm} \times 19 \mathrm{~cm})$ with free access to a running wheel (diameter: $15 \mathrm{~cm}$ ).

\section{EXPERIMENT 1: EFFECTS OF RUNNING ON ADULT PROLIFERATION, ADULT NEUROGENESIS AND ON THE DENDRITIC TREE OF DOUBLECORTIN-LABELED IMMATURE NEURONS IN WILD TYPE AND SYNRAS MICE \\ BrdU injections}

For 12 consecutive days control and running animals were daily weighed and received an intraperitoneal injection of $10 \mathrm{mg} / \mathrm{ml}$ $\mathrm{BrdU}$ (bromodeoxyuridine; Sigma) in $0.9 \% \mathrm{NaCl}$ solution (daily dose: $50 \mu \mathrm{g} / \mathrm{g}$ body weight).

\section{Histological procedure}

One day after the last BrdU injection, animals were deeply anaesthetised with a mix of Ketamin-Rompun $(200 \mu \mathrm{g} / \mathrm{g}$ Ketamin Hydrochloride and $5 \mu \mathrm{g} / \mathrm{g}$ Rompun) and were transcardiacally perfused with $50 \mathrm{ml}$ of phosphate buffer saline $(0.1 \mathrm{M})$ followed by $150 \mathrm{ml}$ of ice-cold $4 \%$ paraformaldehyde in PBS. Brains were quickly removed and postfixed overnight. $25-\mu \mathrm{m}$-sections were cut coronally from an ice-cooled block on a sliding microtome through the entire anteroposterior extension of the hippocampi. Sections were collected and stored at $4{ }^{\circ} \mathrm{C}$ in phosphate buffer saline containing $0.01 \% \mathrm{NaN}_{3}$.

For BrdU-labeling, sections were treated with $0.3 \% \mathrm{H}_{2} \mathrm{O}_{2}$ in distilled water for $30 \mathrm{~min}$ and incubated in SSC-formamid (1:1) for $2 \mathrm{~h}$, washed in SSC buffer and once in phosphate buffer saline. Sections were further incubated in $2 \mathrm{~N} \mathrm{HCl}$ for $1 \mathrm{~h}$ at $37^{\circ} \mathrm{C}$ and washed in $0.1 \mathrm{M}$ borate buffer ( $\mathrm{pH}$ 8.5) for $10 \mathrm{~min}$. After extensive washes in PBS, sections were blocked in the PBS containing $0.3 \%$ Triton (incubation buffer), $5 \%$ horse serum and $2 \%$ Mouse-on-Mouse protein (Vector Laboratories) for $1 \mathrm{~h}$, and incubated overnight at $4^{\circ} \mathrm{C}$ with mouse monoclonal anti-BrdU antibody (1:400; Chemicon) diluted in the incubation buffer. After rinses in PBS, the sections were incubated with the biotinylated horse anti-mouse antibody (1:200; Vector Laboratories) diluted in the incubation medium for $1 \mathrm{~h}$ at room temperature. After another set of rinses in PBS, the ABC Elite reagents (Vector Laboratories) were applied for $1 \mathrm{~h}$. The peroxidase reaction was performed using a diaminobenzedine (DAB) black kit (Zymed) according to the manufacturer's instructions mixing $\mathrm{DAB}$ with hydrogen peroxide and nickel-cobalt in an appropriate buffer for 5-10 min.

For the doublecortin staining the sections were not subjected to any pretreatment with the exception of a $\mathrm{H}_{2} \mathrm{O}_{2} 0.3 \% 30$-min incubation. Sections were rinsed in PBS and immediately incubated for $1 \mathrm{~h}$ with $5 \%$ rabbit serum (Vector laboratories) diluted in PBSTriton $0.3 \%$ followed by an overnight-incubation with the primary antibody anti-doublecortin (Santa Cruz; 1:800). A biotinylated secondary anti-goat antibody (Vector laboratories; 1:200) was used. The subsequent steps were done as indicated above.

\section{Evaluation of the dendritic tree of doublecortin-labelled immature neurons}

After labelling the newly born granule cells of the adult dentate gyrus with doublecortin in $60-\mu \mathrm{m}$ brain sections, the length of their fibres and the number of segments (dendritic fibre section between two arborizations) were determined with a Lucida macroscope and reconstructed with a $100 \times$ objective at the granule cell layer of the dorsal hippocampus of five to seven animals per group. The best doublecortin-labelled cells were selected and only doublecortin-positive fibres of the ventral blade of the dentate gyrus were included in the analysis.

\section{EXPERIMENT 2. ROLE OF BDNF IN RUNNING-INDUCED EFFECTS ON PROLIFERATION AND DIFFERENTIATION BDNF quantitative real-time PCR}

Animals were sacrificed by cervical translocation. Hippocampi were quickly microdissected and frozen in liquid nitrogen before being stored at $-80^{\circ} \mathrm{C}$ up to utilisation. Total RNA was extracted using the Nucleospin RNA II kit (Macherey-Nagel) including DNAseI treatment according to the manufacturer's instructions. cDNA was synthesised from total RNA in a $20-\mu l$ reaction mixture containing $1 \times$ reverse transcription buffer (Sensiscript Reverse Transcription kit, Qiagen), $0.5 \mathrm{mM}$ dNTPs (Sensiscript Reverse Transcription kit, Qiagen), $1 \mu \mathrm{M}$ oligo(dT)s (Invitrogen), 10 units of recombinant RNAsin ribonuclease inhibitor (Promega), and $1 \mu$ of reverse 
transcriptase (Sensiscript Reverse Transcription kit, Qiagen). After incubation for $1 \mathrm{~h}$ at $37^{\circ} \mathrm{C}$ and $10 \mathrm{~min}$ at $93^{\circ} \mathrm{C}$ in order to inactivate the reverse transcriptase in a thermocycler (Eppendorf Mastercycler), the reaction was terminated by incubation at $4^{\circ} \mathrm{C}$. Synthesised cDNA was stored at $-20^{\circ} \mathrm{C}$ up to use. The quantitia was carried out in a $20-\mu \mathrm{l}$ reaction with $10 \mu \mathrm{l}$ of $1 \times$ QuantiTect SYBR Green PCR Master Mix, $0.5 \mu \mathrm{M}$ of the forward primer (BDNF: atgccgcaaacatgtctatg; lamin: aggatccaggaattggaggac) and of the reverse primer (BDNF: taatactgtcacacacgctc; lamin: atcactcagctgctgctgctgcat), $1 \mu$ l of the synthesised cDNA and RNAse-free water was added up to the final volume.

The reaction was performed in a Lightcycler ${ }^{\circledR}$ with the following programme: a 15 -min-initial activation step at $95^{\circ} \mathrm{C}, 50$ cycles of $15 \mathrm{~s}$ of denaturation at $94^{\circ} \mathrm{C}, 20 \mathrm{~s}$ at an annealing temperature of $57^{\circ} \mathrm{C}$ and $30 \mathrm{~s}$ of the extension step at $72^{\circ} \mathrm{C}$ during which the fluorescent data collection was performed. A melting step of $30 \mathrm{~s}$ at $65^{\circ} \mathrm{C}$ allowed verifying the single amplification of the amplicon of the calculated Tm. Relative ratios $(R)$ were calculated according to the equation introduced by Pfaffl (2001):

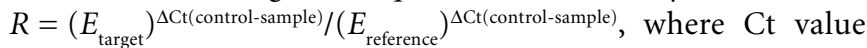
represents the threshold cycle where the fluorescence signal is above background and $E$ the efficiency of the primers. The BDNF (target) mRNA level was normalised to the level of the reference nuclear gene, lamin B1. Calculation of the ratios and statistical analysis were performed using the Relative Expression Software Tool (REST) (Pfaffl et al., 2002).

\section{BDNF ELISA quantification}

Mice were sacrificed by cervical translocation. Hippocampi were quickly dissected and frozen in liquid nitrogen before being stored at $-80^{\circ} \mathrm{C}$ up to utilisation. Samples were thawed and processed with a commercially available BDNF ELISA immunoassay (Promega). The tissue was first homogenised in lysis buffer $(18-\mu \mathrm{l} / \mathrm{mg}$ tissue), containing $137 \mathrm{mM} \mathrm{NaCl}, 20 \mathrm{mM}$ Tris- $\mathrm{HCl}, 1 \% \mathrm{NP} 40,10 \%$ glycerol, $1 \mathrm{mM}$ Phenylmethylsulfonyl fluoride (PMSF), $10 \mu \mathrm{g} /$ $\mathrm{ml}$ aprotinin, $1 \mu \mathrm{g} / \mathrm{ml}$ leupeptin and $0.5 \mathrm{mM}$ sodium vanadate. Samples were further diluted 4:1 with DPBS buffer. The BDNF ELISA immunoassay was then performed according to the manufacturer's instructions. Samples were subjected to acid pretreatment for $15 \mathrm{~min}$ with $1 \mu \mathrm{l}$ of $\mathrm{HCl} 1 \mathrm{~N}$ per $50 \mu \mathrm{l}$ of undiluted sample. A standard curve ranging from 0 to $500 \mathrm{pg} / \mathrm{ml}$ was obtained by serial dilution of BDNF protein standard in Block \& Sample $1 \times$ buffer. All samples and standards were prepared in duplicates. The optical density of the wells was analysed in a TECAN microplate reader at $450 \mathrm{~nm}$ and protein concentrations in the samples were calculated from the standard curve.

\section{Histological procedure for double immunofluorescence labelling}

For double immunofluorescence, sections from wild type mice were incubated for $1 \mathrm{~h}$ in the incubation buffer with $10 \%$ donkey serum, and then incubated overnight with rabbit anti-TrkB (TK-) (1:50; Santa Cruz) in combination with goat anti-doublecortin (1:100; Santa Cruz). The following day, the sections were rinsed in PBS and incubated in the dark with the respective dye-conjugated secondary antibodies (FITC-anti-rabbit, 1:200; Cy3-anti-goat, 1:100; biotinylated anti-mouse, 1:200, later incubated with Cy3-streptavidin, 1:1000) diluted in the incubation buffer. The sections were then rinsed thrice in PBS, the cell nuclei stained for 10 min with the Hoechst 33342 dye (1:1000) and rinsed again with distilled water before mounting with the ProLong Antifade kit (Molecular Probes).

\section{EXPERIMENT 3: EFFECTS OF RUNNING ON NOVELTY RECOGNITION MEMORY}

\section{Novel object recognition task}

The behavioural procedure was similar to that previously described (Sargolini et al., 2003). It consisted of three different phases: a familiarisation phase, a sample phase and a test phase. On the first day mice individually underwent a single 10-min-familiarisation session, during which they were introduced for the first time in a PVC square arena $(50 \mathrm{~cm} \times 50 \mathrm{~cm})$ with $40-\mathrm{cm}$-high walls and a white floor divided into 16 sectors $(12.5 \mathrm{~cm} \times 12.5 \mathrm{~cm})$ by black lines. During this phase, the baseline level of locomotor activity, internal and external crossings, was recorded. On the second day animals were submitted to a single 10-min-sample session (Figure 5A), during which two identical objects (O1 and $\mathrm{O} 2)$ were placed in a symmetric position from the centre of the arena, each $10 \mathrm{~cm}$ from the sidewalls. After a 10-min delay during which mice returned to their home-cage, they were reintroduced into the arena (test session) and exposed for $10 \mathrm{~min}$ to 2 objects, a familiar object: triplicate of the objects presented in the sample session (O3) and a novel object (NO), which substituted one of the previous sample object. Object exploration was evaluated by the time spent in contact by the animals with the objects during the sample and the test sessions. A contact was defined as the subject's snout touching the object from the floor.

\section{Statistical analysis}

All graphs and statistical analysis were performed using the Prism programme (GraphPad) except for the real-time PCR analysis where the REST software (Pfaffl et al., 2002) was used. For the number of labelled cells, BDNF protein levels, the number of segments and the dendritic length, non parametric Mann-Whitney tests were appliedon the mean data of each individual whereas for the behavioural data, parametric analysis of variance were applied. A $p$ value was considered statistically relevant when inferior to 0.05 .

\section{RESULTS}

\section{EXPERIMENT 1: EFFECTS OF RUNNING ON ADULT PROLIFERATION, ADULT NEUROGENESIS AND ON THE DENDRITIC TREE OF DOUBLECORTIN-LABELED IMMATURE NEURONS}

To obtain a better understanding of the mechanisms underlying adult neurogenesis, we examined whether free access to a running wheel could stimulate the reduced adult hippocampal proliferation observed in the synRas mice. All mice were housed per group of five; however, the control mice were in normal standard cages, the running mice were in a bigger cage with free access to a running wheel for 13 days. Control and running mice of both genotypes were daily injected with BrdU (12 injections). The proliferation rate was estimated by counting the number of cells labelled for BrdU per $\mathrm{mm}^{2}$ of the area of the granule cell layer of the hippocampus on one section out of six through the entire hippocampus (from $-1.40 \mathrm{~mm}$ to $-3.40 \mathrm{~mm}$ distance from bregma, according to Paxinos and Franklin, 2001). 
One day after the last of the 12 daily injections, we could observe that under standard control conditions, there were less newborn cells in the synRas mice compared to the wild type NMRI mice $\left(214.83 \pm 23.27\right.$ cells $/ \mathrm{mm}^{2}$ versus $394.17 \pm 37.53$ cells $/ \mathrm{mm}^{2}$ respectively, Mann-Whitney test, $p<0.01$ ) (Figure 1). This was in accordance with previously reported data (Manns et al., in revision).

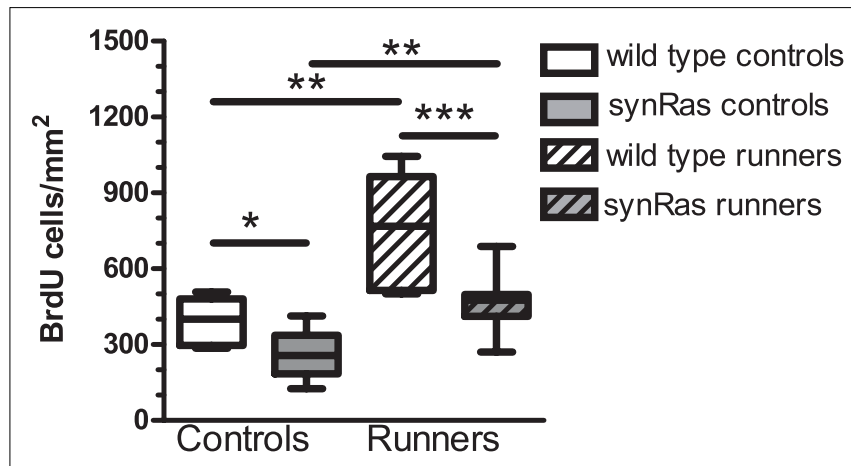

FIGURE 1 | Quantification of the number of bromodeoxyuridine-labeled cells per $\mathrm{mm}^{2}$ in the four different groups: wild type controls $(n=6)$, synRas controls ( $n=8)$, wild type runners $(n=11)$, synRas runners $(n=13)$.
Running stimulated the proliferation rate as revealed by the $160 \%$ increase in the number of BrdU-labeled cells in the wild type running mice compared to the wild type control mice (673.08 \pm 60.27 cells/ $\mathrm{mm}^{2}$ versus $394.17 \pm 37.53$ cells $/ \mathrm{mm}^{2}$ respectively, Mann-Whitney test, $p<0.01)$. A comparable increase $(128 \%)$ of the proliferation rate was also observed in the synRas mice $\left(214.83 \pm 23.27 \mathrm{cells} / \mathrm{mm}^{2}\right.$ in standard conditions compared to $442.20 \pm 25.44 \mathrm{cells} / \mathrm{mm}^{2}$ in the running conditions, Mann-Whitney test, $p<0.01)$. Thus, the basal proliferation rate of the synRas mice was stimulated by running to reach similar levels as in wild type control mice.

In order to show that this paradigm also affected the rate of adult neurogenesis, an immunohistochemical staining for doublecortin, a marker for immature neurons (Figure 2) was performed in wild type and synRas mice housed under standard conditions and with free access to a running wheel after 13 days. The pictures (Figure 2A) gave a qualitative impression of the density and general aspect of the DCX-labeled immature neurons in the dentate gyrus of wild type control mice, wild type running mice, synRas control mice and synRas running mice. The overall density of doublecortin cells in the synRas control mice was lower when compared to the wild type control mice. Yet, this reduction was compensated when the synRas mice were exposed to a bigger

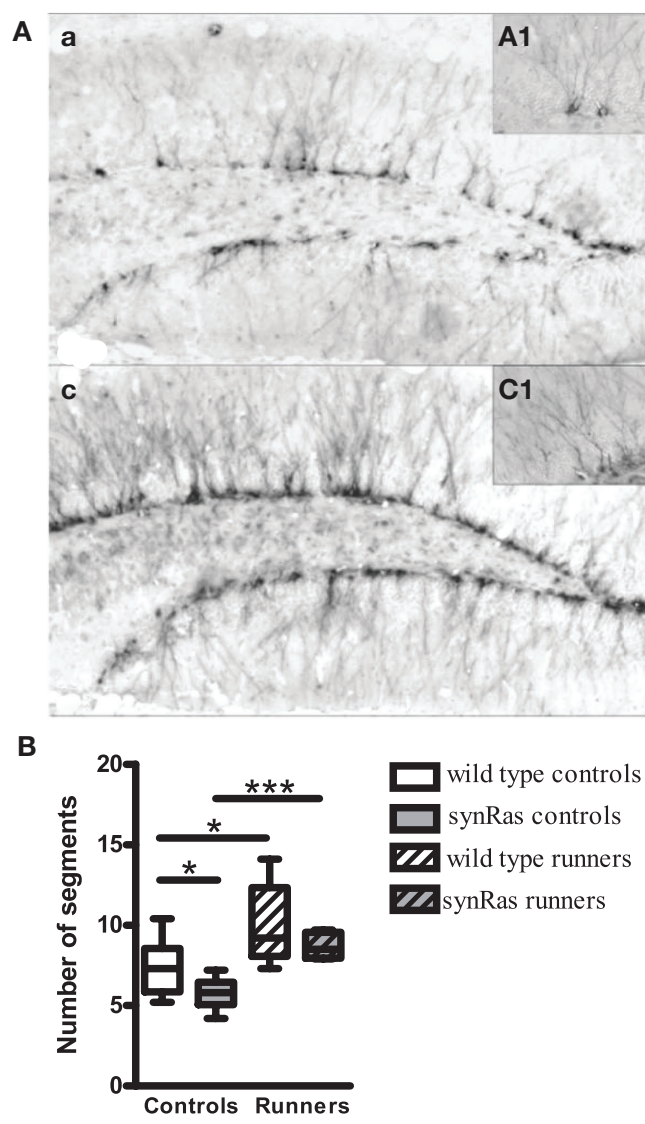

B1

d

D1
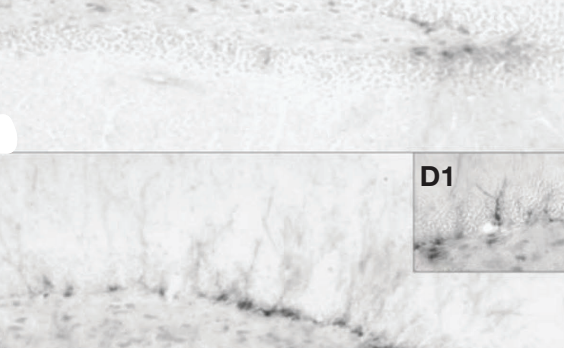

D1
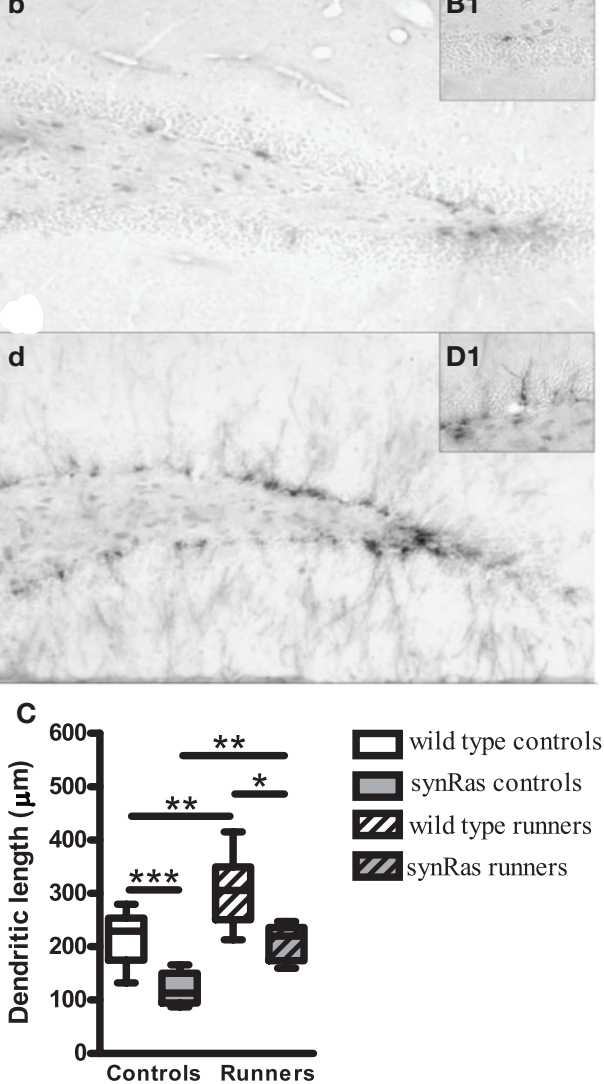

runners $(n=5)$ (d). (B) Effects of physical activity on the number of the segments of immature doublecortin-labeled neurons. (C) Effects of physical activity on the length of the dendrites of immature doublecortin-labeled neurons.

$i^{*}=p<0.05 ;{ }^{*}=p<0.01 ;{ }^{* *}=p<0.001$ according to Mann-Whitney.

FIGURE 2 | Effects of physical activity on the dendritic arborisation of immature doublecortin-labeled neurons. (A) Representative photographs and islets of doublecortin-labeled cells at high magnifier $(\times 100)$ in wild type controls $(n=6)$ (a), synRas controls $(n=6)$ (b), wild type runners $(n=7)(\mathbf{c})$ and synRas 
space with free access to the running wheel, leading to a similar level of doublecortin expression as in wild type control animals. The density of the immature neurons in the running wild type mice was also increased compared to the wild type control mice. The influence of physical activity on the dendritic arborisation of the immature neurons was then estimated by the number of segments and the length of the dendrites of the best labeled doublecortin cells. Physical activity induced an increased number of segments in running wild type and synRas mice compared to their respective non-running controls $(p<0.05$ and $p<0.01$, respectively) (Figure 2B). No difference in the number of segments was observed between the two groups in any housing conditions. Similarly, physical activity lead to longer dendrites in wild type and synRas mice (Figure $2 \mathrm{C}, p<0.05$ ) suggesting that running was able to overcome the Ras supressed dendrite growth in doublecortin neuronal precursor cells.

\section{EXPERIMENT 2: INVOLVEMENT OF BDNF IN RUNNING-INDUCED EFFECTS ON PROLIFERATION AND DIFFERENTIATION}

In order to analyse whether BDNF was associated with the effects of running on cell proliferation, its relative hippocampal mRNA level was determined. No significant difference in the BDNF expression between the wild type and the synRas groups was detected in runners and non-runners (Figure 3). However, after 13 days of voluntary physical activity, the mRNA level of the BDNF gene was significantly increased compared to the wild type control group in the wild type runner group (2.2-fold increase, $p<0.05)$ and in the synRas runner group (2.6-fold increase, $p<0.05 ; 2.0$-fold increase compared to the synRas control group, $p<0.05)$. An ELISA assay was performed in order to test whether the BDNF mRNA increase translated into an increase of BDNF protein. No significant difference was found between the wild type and the synRas mice in runners and non-runners (Mann-Whitney, $p>0.05$ ). After 13 days of exercise, the level of BDNF protein was significantly increased in the wild type mice $(p<0.05)$ whereas in the synRas mice the increase was apparent but did not reach significance $(p>0.05)$.

\section{Determination of TrkB expressing cells}

During adult neurogenesis, cells undergo successive developmental stages from a precursor cell to a mature granule cell (Kempermann et al., 2004). In order to determine whether immature neurons could react to the running-induced increase of BDNF, a double immunohistochemical staining for the BDNF receptor TrkB and doublecortin was performed on wild type sections. As shown in Figure 4, some doublecortin cells expressed the TrkB receptors. However, the expression of the TrkB receptor can occur at different stages of differentiation because it was observed on DCX-positive cells with no or short dendrites as well as on cells with complex dendritic arbors. This suggested that BDNF could act not only on very immature proliferative DCX cells but also on more differentiated neurons.

\section{EXPERIMENT 3: EFFECTS OF RUNNING ON NOVELTY RECOGNITION MEMORY}

As it has been suggested a strong correlation between the level of adult neurogenesis and the behavioural performances of hippocampal-dependent tasks (Shors et al., 2001; Drapeau et al., 2003; Jessberger et al., 2009), the possible correlation between adult neurogenesis and the reaction to object substitution was examined. Indeed, in the test session (Figure 5), 10 min after the presentation of the sample objects, the wild type female animals were able to selectively explore the NO, compared to the familiar one ( $t$-test, $p<0.05)$, indicating that they had recognised the object substitution. In contrast, the synRas mice with a highly reduced adult hippocampal cell proliferation and neurogenesis, did not spend more time exploring the NO compared to the familiar object ( $t$-test, $p>0.05$ ), suggesting that wild type mice interacted more with the NO whereas the synRas mice did not (genotype effect $p<0.01$, object category effect $p<0.01)$. Moreover, the two-way ANOVA revealed a high genotype effect $(p<0.01)$ and a significant object effect $(p<0.01)$ but no interaction genotype $\times$ object category $(p>0.05)$. Simple effect analysis showed high significant difference between the wild type and the synRas mice in the exploration of the familiar object $(t$-test, $p<0.01)$ and the NO $(t$-test, $p<0.05)$. As running stimulated adult proliferation and neurogenesis, voluntary physical activity enhanced object recognition performance in wild type mice as they selectively explored the NO, compared to the familiar one ( $t$-test, $p<0.05)$. Similarly, runner synRas mice were able to react to the object substitution ( $t$-test, $p<0.05)$.
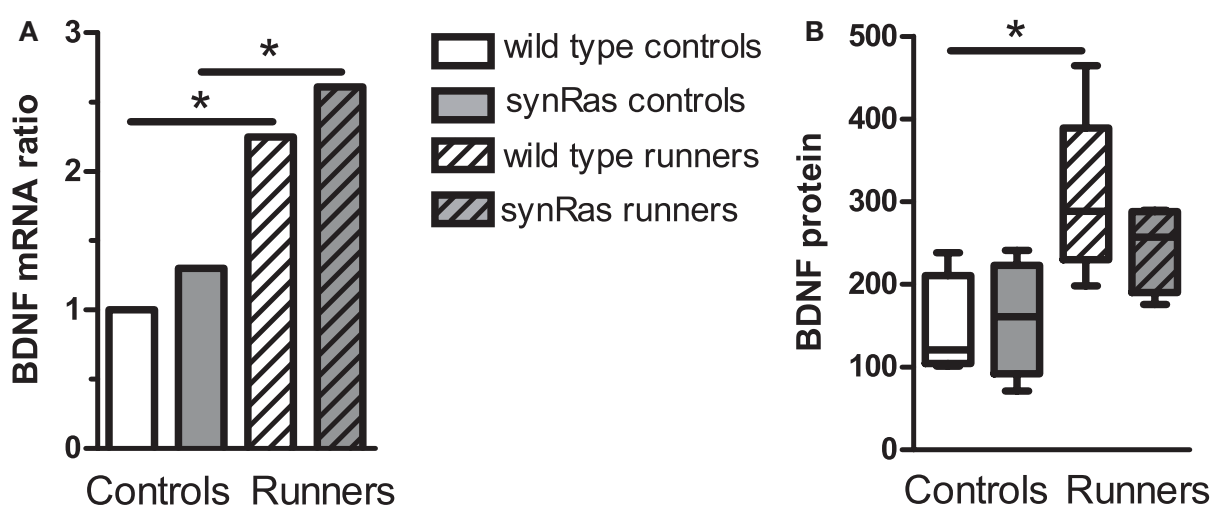

FIGURE 3 | Effects of physical activity on BDNF mRNA expression in wild type controls $(n=6)$, synRas controls $(n=5)$, wild type runners $(n=5)$, synRas runners $(n=5)(A)$ and protein expression $(B)$ in wild type controls $(n=4)$, synRas controls $(n=4)$, wild type runners $(n=5)$, synRas runners $(n=4)$. 

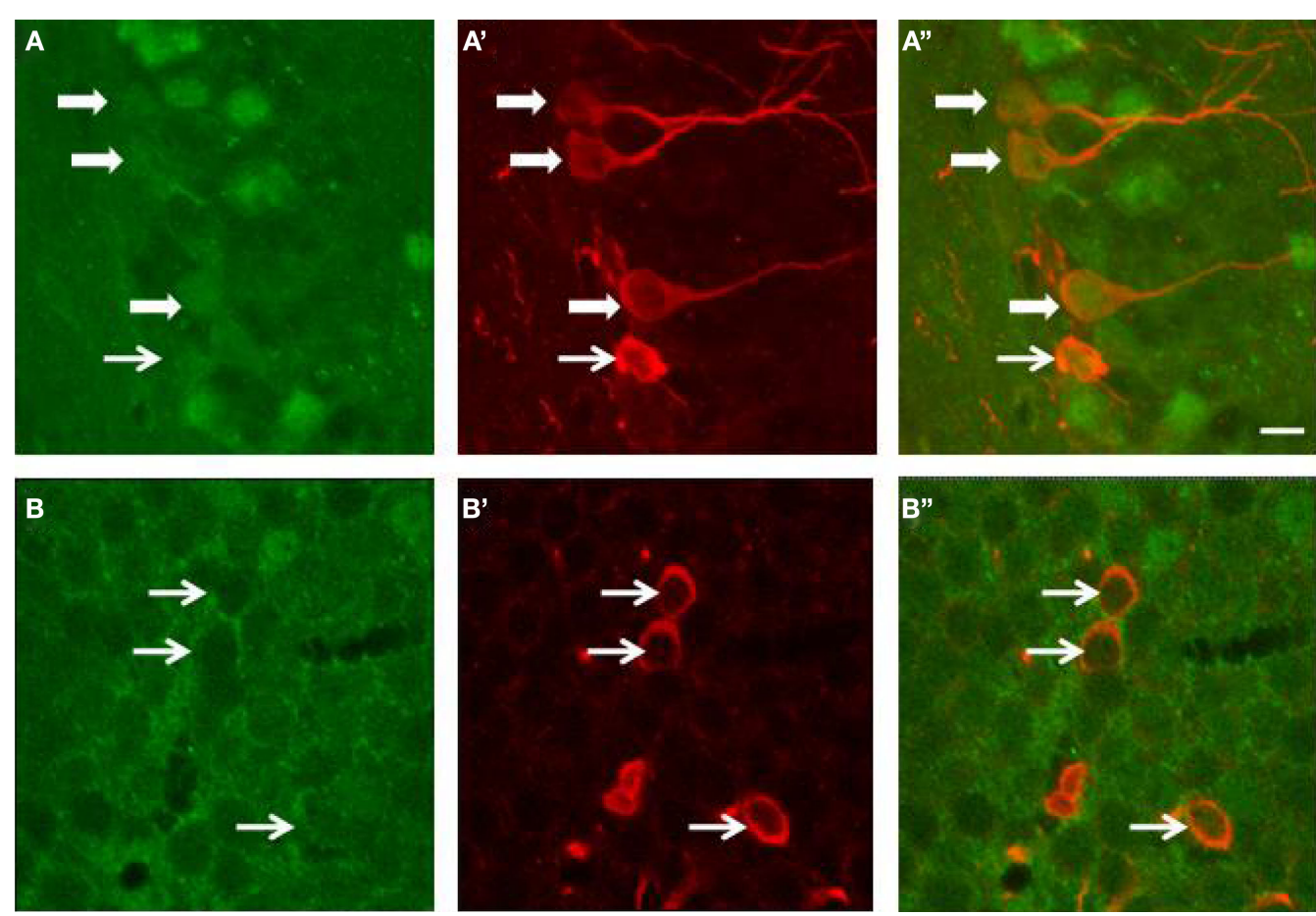

FIGURE 4 | Expression of TrkB receptors (green) by doublecortin (red)-labeled cells of the dentate gyrus of wild type mice. ( $A, B$ ) TrkB expression; ( $A^{\prime}, B^{\prime}$ ) Doublecortin expression; ( $\mathbf{A}^{\prime \prime} \mathbf{B}$ ") merge. White arrows point to doublecortin-immunoreactive cells (with or without processes) that express the TrkB receptors. The bar represents $8 \mu \mathrm{m}$.

\section{DISCUSSION}

We demonstrate here that the decrease in adult proliferation and neurogenesis and the morphological deficits in DCX-positive immature neurons observed in the synRas mouse model are reversed by voluntary physical activity. Our data support the view of an involvement of BDNF. Most interestingly, the running-induced rescue of proliferation and differentiation correlates with a rescue of recognition memory as indicated by an improvement of object exploration and discrimination.

In the synRas model, endogenously regulated Ras is coexpressed with permanently activated Ras in neurons under the direction of the synapsin-1 promoter leading to enhanced morphological differentiation (Heumann et al., 2000) and survival of mature neurons (Manns et al., in revision). This is associated with a decreased proliferation of early proliferating cells due to a non cell autonomous mechanism because neural precursor cells do not express the Ras transgene (Chakrabarty and Heumann, 2008). However, the underlying mechanisms are yet tob e elucidated.

We report here that voluntary physical activity, an ethologically relevant paradigm, reverses this strong synRas phenotype even after a relatively short exposure to a running wheel, demonstrating the plasticity if this system. The effects of voluntary physical activity on adult neurogenesis were observed in the NMRI mice. This corroborates with previous results obtained in the C57BL/6 and Hsd:ICR strains (van Praag et al., 1999) and argues for strain-independent effects of running.

The degree to which proliferation was stimulated was not different in the wild type and the synRas mice. However, the basal level of proliferation was significantly lower in the synRas mice. Yet the hippocampal level of BDNF was not significantly different which suggested that BDNF is not the cause for the generally low proliferation in synRas mice. Consequently, these data suggest that the ways in which basal proliferation is negatively regulated by differentiated neurons differ from the mechanisms by which physical activity promotes proliferation. This is in accordance with a report that suggested regulatory context-dependent mechanisms of proliferation (Kitamura et al., 2003). Indeed the basal level of adult proliferation in mice lacking the NMDA receptor $\varepsilon 1$ subunit were as high as in the wild type mice (Kitamura et al., 2003) but physical activity failed to stimulate adult hippocampal proliferation of these mice. Besides, voluntary physical activity is not always sufficient and failed to rescue hippocampal proliferation in a mouse model of Huntington disease (Kohl et al., 2007).

Previous work has implicated BDNF in adult neurogenesis and differentiation. BDNF infusion can increase the number of newly generated neurons in the adult rat hippocampus (Scharfman et al., 2005). Indeed, the TrkB receptor is present on progenitor cells and its deficiency impairs adult neurogenesis (Bergami et al., 2008; Li et al., 2008). Donovan et al. (2008) demonstrated the receptor on cells in various stages of differentiation. Our double-labeling confirms the presence of the TrkB receptor on immature and more differentiated DCX-positive cells suggesting that BDNF can act on different stages to stimulate adult proliferation and neurogenesis.

As expected, running for 13 days increased the hippocampal BDNF mRNA in wild type and a comparable increase was seen 
A
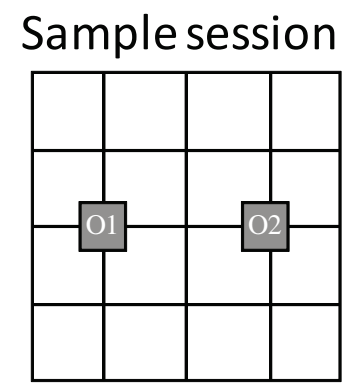

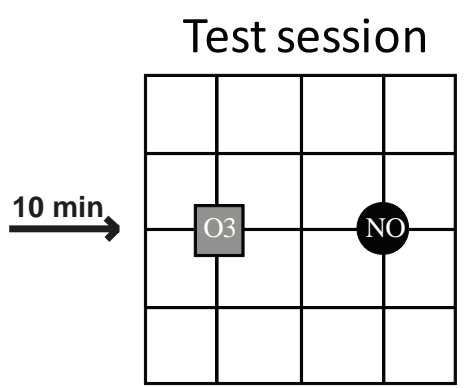

B

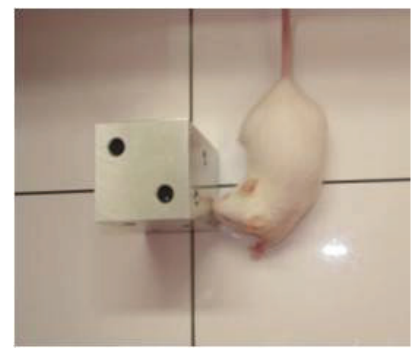

C

D
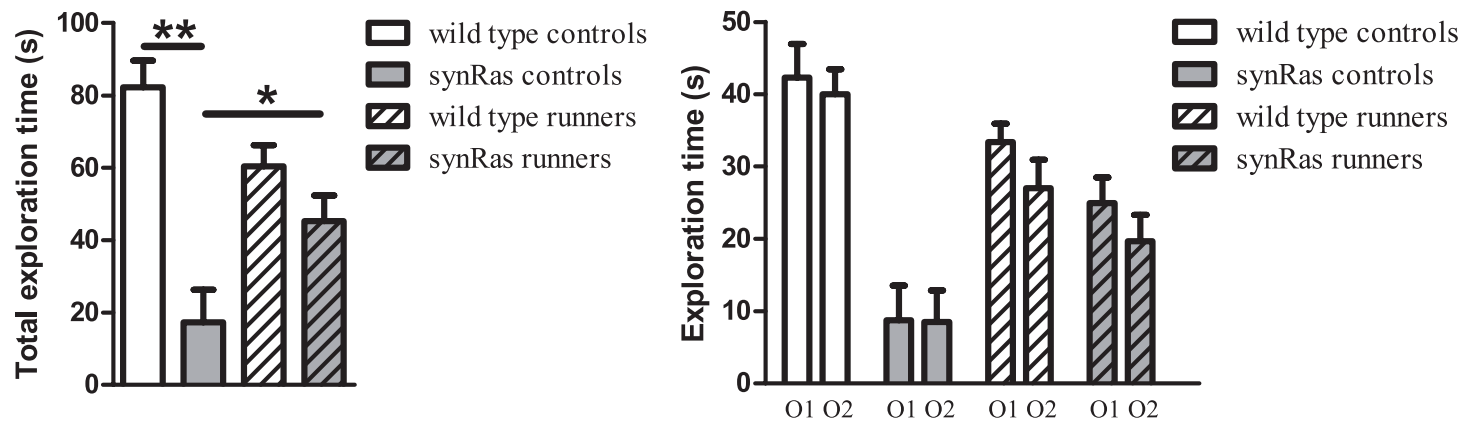

$\mathrm{E}$

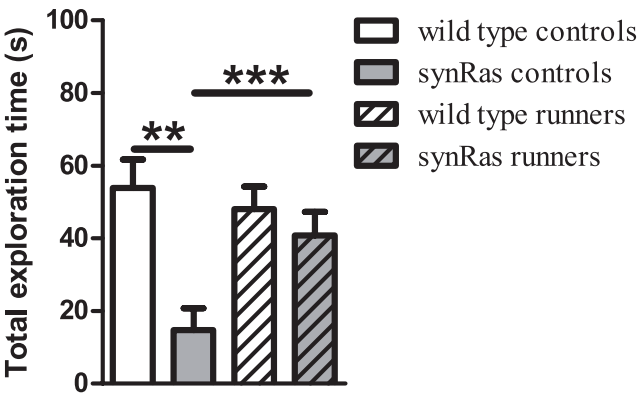

$\mathbf{F}$

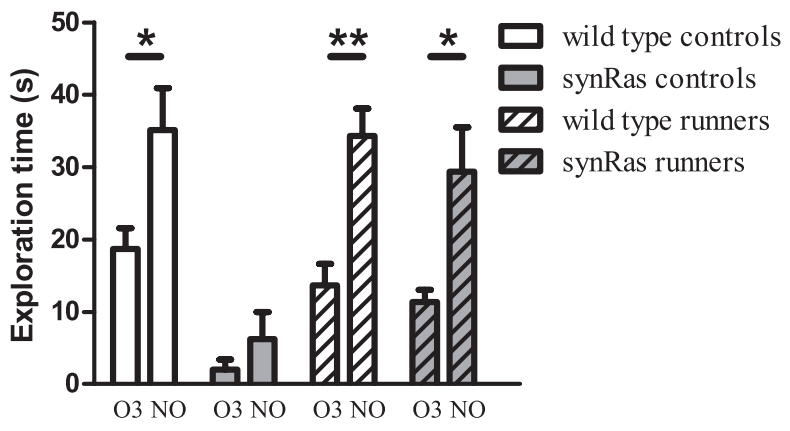

FIGURE 5 | Effects of physical activity on object recognition memory. (A) Schematic representation of the experimental protocol. During the sample session, mice were exposed to two identical objects $\mathrm{O} 1$ and $\mathrm{O} 2$. During the test session, mice were exposed to a triplicate of the familiar object $\mathrm{O} 3$ and a novel object NO. (B) Example of a snout contact with an object. (C) Total exploration duration during the sample session.

in synRas mice. Moreover, the BDNF protein levels increased in both genotypes. The beneficial effects of physical activity could thus be mediated by BDNF which is secreted in an activity-dependend manner (Canossa et al., 2001; Lessmann et al., 2003) and could stimulate the cell division of early proliferating cells either directly as suggested by the recent TrkB deletion models (Li et al., 2008) or indirectly e.g. by promoting synaptic activity and neurotransmitter release (Chan et al., 2008). Further, a wealth of studies has implicated BDNF in dendritogenesis (Davies et al., 1986; McAllister et al., 1995, 1997) suggesting that the enhanced production of BDNF in mice of both genotypes directly explains the running-induced increase in dendritic complexity. Moreover, BDNF is important for cognition as shown at the level of synaptic transmission and plasticity (Schuman, 1999; Lu, 2003) and higher functions in animals (Mizuno
(D) Exploration duration of the specific objects during the sample session (E) Total exploration duration for each group during the test session. (F) Duration of object exploration for each object (triplicate $\mathrm{O} 3$ and novel object NO) during the test session. Wild type controls ( $n=10)$, synRas controls ( $n=8)$, wild type runners $(n=12)$, synRas runners $(n=11)$. ${ }^{*}=p<0.05 ;{ }^{* *}=p<0.01 ;{ }^{* * *}=p<0.001$. et al., 2000; Monteggia et al., 2004), and humans carrying mutations causing an impairment of activity-dependent BDNF secretion (Egan et al., 2003). The enhanced production of BDNF thus correlates well with the clear improvement of wild type and synRas mice in the behavioral task employed in the present study.

Here we could observe a rescue not only of the reduced adult hippocampal neurogenesis but also of impaired cognitive functions. The relationship between neurogenesis and object recognition has recently been shown in rats (Jessberger et al., 2009). This test relies on the integrity of the hippocampus and specifically of the connectivity between the dentate gyrus and the CA3. Indeed, novelty recognition memory is assimilated to an episodiclike memory (Kesner, 2007). For unknown reasons, the synRas mice show a general lack of interest for the objects and a reduced 
exploration in the sample and test sessions. It has recently been shown that the TrkB signalling cascade is involved in the modulation of anxiety levels: genetic deletion of this receptor in the dentate gyrus leads to a decrease in exploratory behaviour in a novel environment and in the elevated plus maze (Bergami et al., 2008). Therefore, a possible explanation could have been that the synRas mice show higher levels of anxiety in control conditions. This was however not the case in our system as no difference in any of the anxiety tests (open-field, elevated plus maze and dark-light box) were observed (data not shown). This low exploration level did not allow mice to properly encode information about the objects and to later discriminate them. However, when the synRas mice were exposed to a running wheel for 13 days, there was a dramatical increase of this ability. The present data not only show that the wild type running mice performed better but also that the running synRas mice could detect and react to the object substitution after exercising.

Chronic forced exercise could restore interferon-alpha-induced learning deficits in NO recognition (Fahey et al., 2008). Here we demonstrate that voluntary physical activity enhances object recognition memory in unlesioned synRas mice, suggesting that in some cases, exercise can be a way to recover from geneticallyinduced impaired behavioural abilities. It has already been proposed that hippocampal-dependent task performance predicts hippocampal neurogenesis (Shors et al., 2001; Drapeau et al., 2003) or that there is a reciprocal action of learning and adult neurogenesis (van Praag et al., 1999; Cao et al., 2004; Snyder et al., 2005; Olson et al., 2006; Dupret et al., 2008). Running has

\section{REFERENCES}

Adlard, P. A., and Cotman, C. W. (2004). Voluntary exercise protects against stress-induced decreases in brainderived neurotrophic factor protein expression. Neuroscience 124 , 985-992.

Adlard, P. A., Perreau, V. M., EngesserCesar, C., and Cotman, C. W. (2004). The timecourse of induction of brainderived neurotrophic factor mRNA and protein in the rat hippocampus following voluntary exercise. Neurosci. Lett. 363, 43-48.

Berchtold, N. C., Kesslak, J. P., Pike, C.J., Adlard, P. A., and Cotman, C. W. (2001). Estrogen and exercise interact to regulate brain-derived neurotrophic factor mRNA and protein expression in the hippocampus. Eur. J. Neurosci. 14, 1992-2002.

Bergami, M., Rimondini, R., Santi, S. Blum, R., Götz, M., and Canossa, M. (2008). Deletion of TrkB in adult progenitors alters newborn neuron integration into hippocampal circuits and increases anxiety-like behavior. Proc. Natl. Acad. Sci. U.S.A. 105, 15570-15575.

Binder, E., Droste, S. K., Ohl, F., and Reul, J. M. (2004). Regular voluntary exercise reduces anxiety-related behaviour and impulsiveness in mice. Behav. Brain Res. 155, 197-206.
Borasio, G. D., John, J., Wittinghofer, A., Barde, Y. A., Sendtner, M., and Heumann, R. (1989). Ras p21 protein promotes survival and fiber outgrowth of cultured embryonic neurons. Neuron 2, 1087-1096.

Brown, J., Cooper-Kuhn, C. M., Kempermann, G., Van Praag, H., Winkler,J., Gage, F.H., and Kuhn, H. G. (2003). Enriched environment and physical activity stimulate hippocampal but not olfactory bulb neurogenesis. Eur. J. Neurosci. 17, 2042-2046.

Canossa, M., Gärtner, A., Campana, G., Inagaki, N., and Thoenen, H. (2001). Regulated secretion of neurotrophins by metabotropic glutamate group I (mGluRI) and Trk receptor activation is mediated via phospholipase C signalling pathways. EMBO J. 20, 1640-1650.

Cao, L., Jiao, X., Zuzga, D. S., Liu, Y., Fong, D M., Young, D., and During, M. J. (2004). VEGF links hippocampal activity with neurogenesis, learning and memory. Nat. Genet. 36, 827-835.

Chakrabarty, K., and Heumann, R. (2008). Prospective of Ras signaling in stem cells. Biol. Chem. 389, 791-798.

Chakrabarty, K., Serchov, T. Mann, S. A., Dietzel, I. D., and Heumann, R. (2007). Enhancement of dopaminergic properties and

been shown to improve performance in other behavioural tasks (van Praag et al., 1999; Binder et al., 2004) and exercise-induced neurogenesis was associated with spatial memory recovery in the Morris water maze in a stroke model (Luo et al., 2007). The present data complement the idea that there is an important correlation between adult neurogenesis and episodic-like memory. A possible explanation would be that exercise would induce longterm potentiation (LTP) in hippocampal neurons leading to better performance in recognition memory tasks and stimulating the proliferation and differentiation of newly generated neurons. Indeed, exercise has been shown to induce LTP, a cellular correlate of learning and memory (Vasuta et al., 2007). Moreover, recognition memory and LTP are intimately linked (Wang et al., 2004; Hennigan et al., 2008).

A number of environmental stimuli such as social stress or longterm light deprivation or normal ageing may lead to a downregulation of neurogenesis and cognitive functions. Using a genetically modified mouse model exhibiting a BDNF-independent downregulation of hippocampal neurogenesis with genetically induced deficiencies in cognition we demonstrate voluntary physical activity has a robust beneficial effect that could also be beneficial in therapies.

\section{ACKNOWLEDGMENTS}

We thank the DFG Graduate Programme 736 and the GK "Development and Plasticity of the Nervous System" for their financial support and Dr. Martina Manns for her technical expertise and advice.

protection mediated by neuronal activation of Ras in mouse ventral mesencephalic neurones. Eur. J. Neurosci. 25, 1971-1981.

Chan, J. P., Cordeira, J., Calderon, G. A., Iyer, L. K., and Rios, M. (2008). Depletion of central BDNF in mice impedes terminal differentiation of new granule neurons in the adult hippocampus. Mol. Cell Neurosci. 39, 372-383.

Clark, R. E., West,A. N.,Zola, S. M., Squire, and L. R. (2001). Rats with lesions of the hippocampus are impaired on the delayed nonmatching-to-sample task. Hippocampus 11, 176-186.

Dalla, C., Papachristos, E. B., Whetstone, A. S., and Shors, T. J. (2009). Female rats learn trace memories better than male rats and consequently retain a greater proportion of new neurons in their hippocampi. Proc. Natl. Acad. Sci. U.S.A. 106 2927-2932.

Davies,A.M., Thoenen,H., and Barde, Y. A. (1986). The response of chick sensory neurons to brain-derived neurotrophic factor. J. Neurosci. 6, 1897-1904.

Donovan, M. H., Yamaguchi, M., and Eisch,A.J.(2008). Dynamic expression of $\operatorname{TrkB}$ receptor protein on proliferating and maturing cells in the adult mouse dentate gyrus. Hippocampus 18, 435-439.
Drapeau, E., Mayo, W., Aurousseau, C., Le Moal, M., Piazza, P. V., and Abrous, D. N. (2003). Spatial memory performances of aged rats in the water maze predict levels of hippocampal neurogenesis. Proc. Natl. Acad. Sci. U.S.A. 100, 14385-14390.

Dupret, D., Revest, J. M., Koehl, M., Ichas, F., De Giorgi, F., Costet, P., Abrous, D. N., and Piazza, P.V. (2008). Spatial relational memory requires hippocampal adult neurogenesis. PLoS ONE 3, e1959. doi: 10.1371/journal. pone.0001959.

Egan, M. F., Kojima, M., Callicott, J. H., Goldberg, T. E., Kolachana, B. S., Bertolino, A., Zaitsev, E., Gold, B., Goldman, D., Dean, M., Lu, B., and Weinberger, D. R. (2003). The BDNF val66met polymorphism affects activity-dependent secretion of BDNF and human memory and hippocampal function. Cell 112, 257-269.

Fahey, B., Barlow, S., Day, J. S., and O’Mara, S. M. (2008). Interferonalpha-induced deficits in novel object recognition are rescued by chronic exercise. Physiol. Behav. 95, 125-129.

Felderhoff-Mueser, U., Bittigau, P., Sifringer, M., Jarosz, B., Korobowicz, E., Mahler, L., Piening, T., Moysich, A., Grune, T., Thor, F., Heumann, R., Bührer, C., and Ikonomidou, C. (2004). Oxygen causes cell death in 
the developing brain. Neurobiol. Dis. 17, 273-282.

Feria-Velasco, A., del Angel, A. R., and Gonzalez-Burgos, I. (2002). Modification of dendritic development. Prog. Brain Res. 136, 135-143.

Garthe, A., Behr, J., and Kempermann, G. (2009). Adult-generated hippocampal neurons allow the flexible use of spatially precise learning strategies. PLoS ONE 4, e5464. doi: 10.1371/journal. pone.0005464.

Hennigan, A., Callaghan, C. K., Kealy, J., Rouine, J., and Kelly, A. M. (2008). Deficits in LTP and recognition memory in the genetically hypertensive rat are associated with decreased expression of neurotrophic factors and their receptors in the dentate gyrus. Behav. Brain Res. 197, 371-377.

Hernández-Rabaza, V., LlorensMartín, M., Velázquez-Sánchez, C., Ferragud, A., Arcusa, A., Gumus, H. G., Gómez-Pinedo, U., Pérez-Villalba, A., Roselló, J., Trejo, J. L., Barcia, J. A., and Canales, J. J. (2009). Inhibition of adult hippocampal neurogenesis disrupts contextual learning but spares spatial working memory, long-term conditional rule retention and spatial reversal. Neuroscience 159, 59-68.

Heumann, R., Goemans, C., Bartsch, D., Lingenhohl, K., Waldmeier, P. C., Hengerer, B., Allegrini, P. R., Schellander, K., Wagner, E. F., Arendt, T., Kamdem, R. H., ObstPernberg, K., Narz, F., Wahle, P. and Berns, H. (2000). Transgenic activation of Ras in neurons promotes hypertrophy and protects from lesioninduced degeneration. J. Cell Biol. 151, 1537-1548.

Jessberger, S., Clark, R. E., Broadbent, N. J., Clemenson, G. D., Jr., Consiglio, A., Lie, D.C., Squire, L. R., and Gage, F. H. (2009). Dentate gyrus-specific knockdown of adult neurogenesis impairs spatial and object recognition memory in adult rats. Learn. Mem. 16, 147-154.

Johnson, R. A., Rhodes, J. S., Jeffrey, S. L., Garland, T., Jr., and Mitchell, G. S. (2003). Hippocampal brain-derived neurotrophic factor but not neurotrophin-3 increases more in mice selected for increased voluntary wheel running. Neuroscience 121, 1-7.

Kempermann, G. (2002). Why new neurons? Possible functions for adult hippocampal neurogenesis. $J$. Neurosci. 22, 635-638.

Kempermann, G., Jessberger,S., Steiner, B., and Kronenberg, G. (2004). Milestones of neuronal development in the adult hippocampus. Trends Neurosci. 27, 447-452.

Kesner, R. P. (2007). Behavioral functions of the CA3 subregion of the hippocampus. Learn. Mem. 14, 771-781.
Kitamura, T., Mishina, M., and Sugiyama, H. (2003). Enhancement of neurogenesis by running wheel exercises is suppressed in mice lacking NMDA receptor epsilon 1 subunit. Neurosci. Res. 47, 55-63.

Kohl, Z., Kandasamy, M., Winner, B., Aigner, R., Gross, C., CouillardDespres, S., Bogdahn, U., Aigner, L., and Winkler, J. (2007). Physical activity fails to rescue hippocampal neurogenesis deficits in the R6/2 mouse model of Huntington's disease. Brain Res. 1155, 24-33.

Leggio, M. G., Mandolesi, L., Federico, F., Spirito, F., Ricci, B., Gelfo, F., and Petrosini, L. (2005). Environmental enrichment promotes improved spatial abilities and enhanced dendritic growth in the rat. Behav. Brain Res. $163,78-90$.

Lessmann, V., Gottmann, K., and Malcangio, M. (2003). Neurotrophin secretion: current facts and future prospects. Prog. Neurobiol. 69, 341-374.

Li, Y., Luikart, B. W., Birnbaum, S., Chen, J., Kwon, C. H., Kernie, S. G., Bassel-Duby, R., and Parada, L. F. (2008). TrkB regulates hippocampal neurogenesis and governs sensitivity to antidepressive treatment. Neuron $59,399-412$.

Lu, B. (2003). BDNF and activitydependent synaptic modulation. Learn. Mem. 10, 86-98.

Luo, C.X., Jiang, J.,Zhou, Q. G., Zhu, X. J., Wang, W., Zhang, Z. J., Han, X., and Zhu, D. Y. (2007). Voluntary exercise-induced neurogenesis in the postischemic dentate gyrus is associated with spatial memory recovery from stroke. J. Neurosci. Res. 85, 1637-1646.

Makwana, M., Serchov, T., Hristova, M., Bohatschek, M., Gschwendtner, A., Kalla, R., Liu, Z., Heumann, R., and Raivich, G. (2009). Regulation and function of neuronal GTP-Ras in facial motor nerve regeneration. J. Neurochem. 108, 1453-1463.

Manns, J. R., Hopkins, R. O., Reed, J. M., Kitchener, E. G., and Squire, L. R. (2003). Recognition memory and the human hippocampus. Neuron 37 , 171-180.

McAllister, A. K., Katz, L. C., and Lo, D. C. (1997). Opposing roles for endogenous BDNF and NT-3 in regulating cortical dendritic growth. Neuron 18 , 767-778.

McAllister,A. K., Lo, D. C., and Katz, L. C. (1995). Neurotrophins regulate dendritic growth in developing visual cortex. Neuron 15, 791-803.

Mizuno, M., Yamada, K., Olariu, A., Nawa, H., and Nabeshima, T. (2000). Involvement of brain-derived neurotrophic factor in spatial memory formation and maintenance in a radial arm maze test in rats. J. Neurosci. 20 7116-7121.

Monteggia,L.M., Barrot,M.,Powell, C. M., Berton, O., Galanis, V., Gemelli, T., Meuth, S., Nagy, A., Greene, R. W., and Nestler, E. J. (2004). Essential role of brain-derived neurotrophic factor in adult hippocampal function. Proc. Natl. Acad. Sci. U.S.A. 101, 10827-10832.

Moser, M. B., Trommald, M., and Andersen, P. (1994). An increase in dendritic spine density on hippocampal CA1 pyramidal cells following spatial learning in adult rats suggests the formation of new synapses. Proc. Natl. Acad. Sci. U.S.A. 91, 12673-12675

Murray, E.A., Bussey, T. J., Hampton, R. R., and Saksida, L. M. (2000). The parahippocampal region and object identification. Ann. N. Y. Acad. Sci. 911, 166-174.

Olson, A. K., Eadie, B. D., Ernst, C., and Christie, B. R. (2006). Environmental enrichment and voluntary exercise massively increase neurogenesis in the adult hippocampus via dissociable pathways. Hippocampus 16, 250-260.

Paxinos, G., and Franklin, K. B. J. (2001) The mouse brain in stereotaxic coordinates. Academic Press, San Diego.

Pfaffl, M. W. (2001). A new mathematical model for relative quantification in real-time RT-PCR. Nucleic Acids Res. 29, e45.

Pfaffl, M. W., Horgan, G. W., and Dempfle, L. (2002). Relative expression software tool (REST) for group-wise comparison and statistical analysis of relative expression results in real-time PCR. Nucleic Acids Res. 30, e36.

Russo-Neustadt, A. A., Alejandre, H., Garcia, C., Ivy, A. S., and Chen, M. J. (2004). Hippocampal brain-derived neurotrophic factor expression following treatment with reboxetine, citalopram, and physical exercise. Neuropsychopharmacology 29 , 2189-2199.

Sargolini, F., Roullet, P., Oliverio, A. and Mele, A. (2003). Effects of intraaccumbens focal administrations of glutamate antagonists on object recognition memory in mice. Behav. Brain Res. 138, 153-163.

Scharfman, H., Goodman, J., Macleod, A. Phani, S., Antonelli, C., and Croll, S. (2005). Increased neurogenesis and the ectopic granule cells after intrahippocampal BDNF infusion in adult rats. Exp. Neurol. 192, 348-356.

Schuman, E. M. (1999). Neurotrophin regulation of synaptic transmission. Curr. Opin. Neurobiol. 9, 105-109.

Shors, T. J., Miesegaes, G., Beylin, A. Zhao, M., Rydel, T., and Gould, E. (2001). Neurogenesis in the adult is involved in the formation of trace memories. Nature 410, 372-376.

Snyder, J. S., Hong, N. S., McDonald, R. J., and Wojtowicz, J. M. (2005). A role for adult neurogenesis in spatial long-term memory. Neuroscience 130, 843-852.

Stranahan,A. M., Khalil, D., and Gould, E. (2007). Running induces widespread structural alterations in the hippocampus and entorhinal cortex. Hippocampus 17, 1017--1022.

van Praag, H., Christie, B. R., Sejnowski, T. J., and Gage, F. H. (1999). Running enhances neurogenesis, learning, and long-term potentiation in mice. Proc. Natl. Acad. Sci. U.S.A. 96, 13427-13431.

Vasuta, C., Caunt, C., James, R., Samadi, S., Schibuk, E., Kannangara, T., Titterness, A. K., and Christie, B. R. (2007). Effects of exercise on NMDA receptor subunit contributions to bidirectional synaptic plasticity in the mouse dentate gyrus. Hippocampus 17, 1201-1208.

Vojtek, A. B., and Der, C. J. (1998). Increasing complexity of the Ras signaling pathway. J. Biol. Chem. 273, 19925-19928

Wang, H., Ferguson, G. D., Pineda, V. V. Cundiff, P.E., and Storm, D. R. (2004). Overexpression of type-1 adenylyl cyclase in mouse forebrain enhances recognition memory and LTP. Nat. Neurosci. 7, 635-642.

Wojtowicz, J. M., Askew, M. L., and Winocur, G. (2008). The effects of running and of inhibiting adult neurogenesis on learning and memory in rats. Eur. J. Neurosci. 27, 1494-1502.

Conflict of Interest Statement: The authors declare that the research was conducted in the absence of any commercial or financial relationships that could be construed as a potential conflict of interest.

Received: 22 June 2009; paper pending published: 16 July 2009; accepted: 18 September 2009; published online: 22 February 2010.

Citation: Lafenêtre $P$, Leske $O, M a-$ Högemeie Z, Haghikia A, Bichler Z, Wahle $P$ and Heumann $R$ (2010) Exercise can rescue recognition memory impairment in a model with reduced adult hippocampal neurogenesis. Front. Behav. Neurosci. 3:34. doi: 10.3389/neuro.08.034.2009

Copyright (C) 2010 Lafenêtre, Leske, MaHögemeie, Haghikia, Bichler, Wahle and Heumann. This is an open-access article subject to an exclusive license agreement between the authors and the Frontiers Research Foundation, which permits unrestricted use, distribution, and reproduction in any medium, provided the original authors and source are credited. 